\title{
Optimal design of Vertical-Taking-Off-and-Landing UAV wing using multilevel approach
}

\author{
Hao Yue ${ }^{1,2, *}$, David Bassir ${ }^{3,4}$, Hicham Medromi ${ }^{1,2}$, Hua Ding $^{5}$, and Khaoula Abouzaid ${ }^{6}$ \\ ${ }^{1}$ National and High School of Electricity and Mechanic (ENSEM), Hassan II University, Casablanca, Morocco \\ ${ }^{2}$ Research Foundation for Development and Innovation in Science and Engineering (FRDISI), Casablanca, Morocco \\ ${ }^{3}$ CNRS/UMR 5060, Université de Technologie de Belfort-Montbéliard, France, France \\ ${ }^{4}$ Centre Borelli, CMLA, ENS Cachan, CNRS, Université Paris-Saclay, 94235 Cachan, France \\ ${ }^{5}$ Institute of Industry Technology, Guangzhou \& Chinese Academy of Sciences (IIT, GZ\&CAS), Guangzhou, PR China \\ ${ }^{6}$ INRAE, Avignon University, UMR EMMAH, F-84000, Avignon, France
}

Received: 31 October 2020 / Accepted: 11 November 2020

\begin{abstract}
In order to overcome the propre disadvantages of FW(Fixed-Wing) and VTOL(Vertical-TakingOff-and-Landing) UAV (Unmanned Aerial Vehicle) and extend its application, the hybrid drone is invested more in recent years by researchers and several classifications are developed on the part of dual system. In this article, an innovative hybrid UAV is raised and studied by introducing the canard configuration that is coupled with conventional delta wing as well as winglet structure. Profited by Computational Fluid Dynamics (CFD) and Response Surface Method (RSM), a multilevel optimization approach is practically presented and concerned in terms of cruise flight mode: adopted by an experienced-based distribution strategy, the total lift object is respectively assigned into the delta wing (90-95\%) and canard wing (5-10\%) which is applied into a twostep optimization: the first optimization problem is solved only with the parameters concerned with delta wing afterwards the second optimization is successively concluded to develop the canard configuration considering the optimized delta wing conception. Above all, the optimal conceptual design of the delta and canard wing is realized by achieving the lift goal with less drag performance in cruise mode.
\end{abstract}

Keywords: Hybrid UAV / canard wing / multilevel optimization approach / RSM / CFD / VTOL

\section{Introduction to hybrid UAV}

During recent decades, the UAVs have attracted amount of interests and researches with the civil and military aim such as logistics, geographical mapping, routine surveillance [1]. Although the hybrid drones are specialized with the ability of VTOL and cruise flying, there are several natural but critical conflicts between two procedures in technology, which stands out in the development of hybrid drone [2]. The dominated conflict is that there is incompatibility in design method between fixed-wing and VTOL cruises because of the differences in thrust vector, which would inventively introduce two major critical drawbacks: (1) complicated "wasteful" structure; (2) unreasonable compromises. Therefore, common problems in hybrid UAVs, such as additional weight in mechanicals, unstable performance in operation, and low

\footnotetext{
* e-mail: yuehao20160719@gmail.com
}

efficiency in energy, arise during design and manufacture which is always the hot spot for researchers to study and improve [3].

The researches Hassanalian and Abdelkef [4] take on a very detailed research on the classification on the UAVs. According to the airframe transition of VTOL and cruise flight, Saeed [5] make a categorized with two types of hybrid drone: convertiplane and tail-sitter, of which the tail-sitter changes its airframe when transition while the convertiplane maintains still all the time. Several subtypes are assigned to in terms of mechanical characters. Meanwhile, according to the advancement in hybrid UAVs' researches in recent years, this article prefers to divide the hybrid drones with the specialization of propulsion system, especially considering the main conflicts of VTOL and FW procedure. Thus, two types of hybrid UAV are discussed above: double-system and single-system. In addition, several sub-types are grouped respectively depending on aerodynamic performance and transition system (see Fig. 1). 


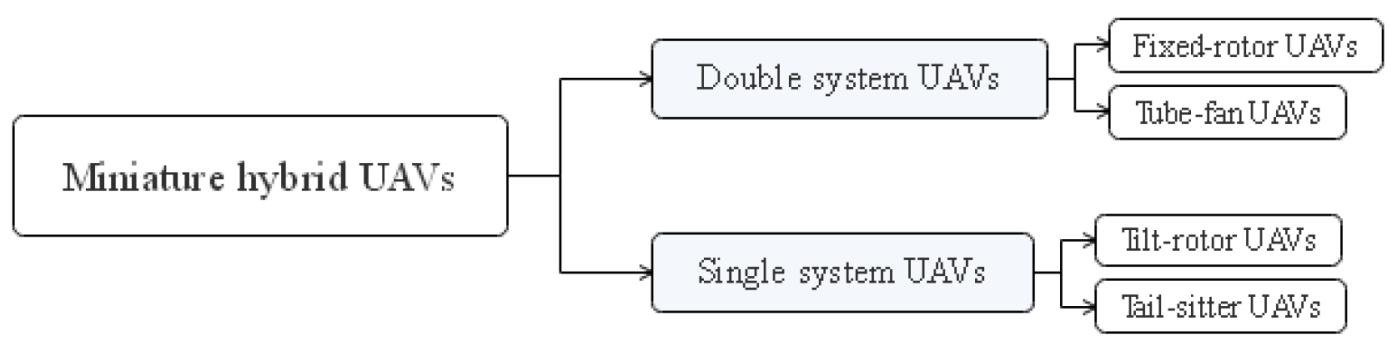

Fig. 1. Classification of hybrid UAV.

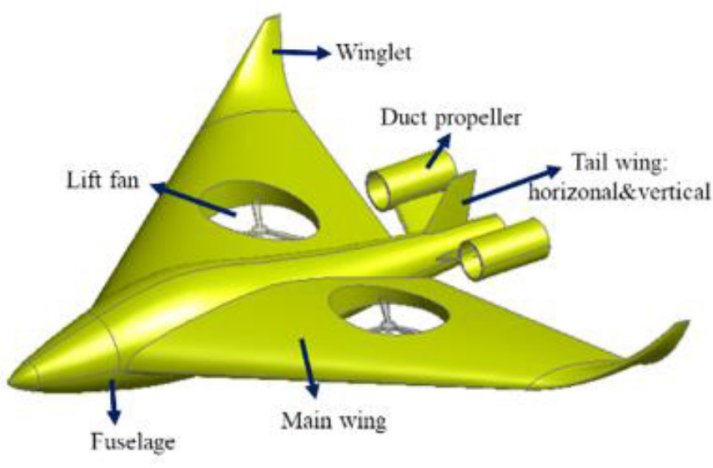

(a)

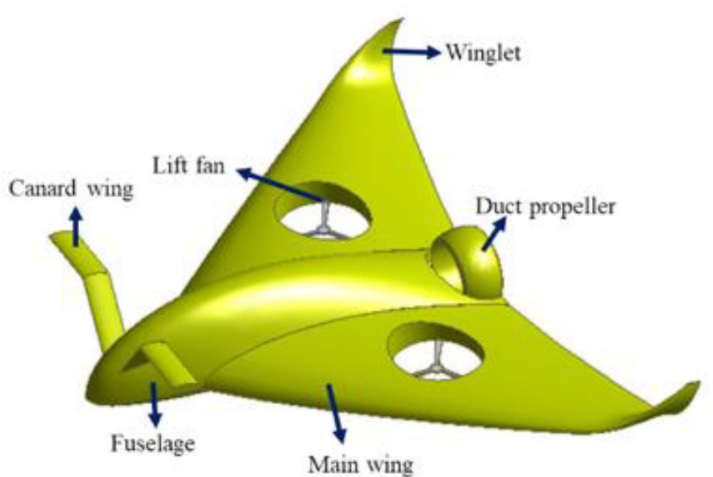

(b)

Fig. 2. Comparisons of the two conceptual design of hybrid UAV (a) preliminary design with winglet (b) present design with canard configuration.

\section{New conceptual UAV design}

With massive precedent researches as well as engineering experience in structural optimization and additive manufacture technologies, our team has invented an innovative conception of Tube-Fan drone characterised with the integration of fixed-wing and tube-fan inside in the wing structure [6], where basic flight modes are included in our hybrid-UAV: (1) cruise mode; (2) VTOL mode; (3) transition mode.

In the preliminary conception, though the winglet was added into the delta wing structure to improve the poor aerodynamical performance caused by the low aspect-ratio (see Fig. 2a), this article continues to adopt the canard configuration which is widely preferred in the modern fixed-wing plane conception, with a slight modification in the fuselage part [6] (see Fig. 2b). As the canard wing are installed at the front of the fuselage of the tube-fan UAV, it's supposed that the lift performance would be increased the lift performance dramatically in the cruise flight mode, as well as its manoeuvrability and low trim drag at the occasion of large angle of attack [7]. Besides, the canard wing would enhance the flight security by preventing into stall thanks to the canard wing while energy economy of the drone is improved by omitting the tail wing part, which would inevitably produce negative lift to keep the attitude balance [8]. Above all, the principal dimensions of the hybrid UAV is fixed as followings: the width and length should be less than 2 meters, while the Maximum Taking-
Off Weight (MTOW) must pass than $30 \mathrm{~kg}$ at the speed of $60 \mathrm{~km} / \mathrm{h}$. Therefore, our hybrid Tube-fan drone would be classified as Small drone [9] or Lightweight UAV small range with the estimated range of $40 \mathrm{~km}$.

Based on the new conception, some requirements in the cruise mode with speed of $60 \mathrm{~km} / \mathrm{h}$ are proposed as following: (1) the total lift Maximum Taking-Off and Landing (VTOL) should be over $30 \mathrm{~kg}$ which means the lift produced by wings would be larger than $300 \mathrm{~N} ;$ (2) the overall length and the width of the UAV couldn't exceed than $2 \mathrm{~m}$ to possess both a good portability and an easily operating condition; (3) It's necessary to reach the light weight of the structure and the minimum drag produced in the cruise speed to save energy. In the forthcoming investigations, focus will be on the integration of composite materials [10] and the reduction of the yield stress on the interfaces of the different component of the structure [11].

Therefore, a multi-objective optimization of the conceptual design of the innovation hybrid UAV, considering only the cruise flight condition, would be stated as follows

$$
\left\{\begin{array}{r}
\text { Minimization of }\left\{F_{x} \cdot M_{w}\right\} \\
\text { s.t. }\left\{\begin{array}{l}
F_{y} \geq 150 N \\
s_{p} \leq 1 \mathrm{~m} \\
L_{c} \leq 1.5 \mathrm{~m}
\end{array}\right.
\end{array}\right.
$$

where $F_{x}, F_{y} M_{w}$ represent respectively the lift, drag and the weight of the half wings (one delta and canard wing), 
Table 1. Results of grid independent verification.

\begin{tabular}{lllllll}
\hline Mesh Strategy & $\begin{array}{l}\text { Quantity } \\
\text { of Grids }\end{array}$ & Lift/N & $\begin{array}{l}\text { Lift change } \\
\text { rate (\%) }\end{array}$ & Drag/N & $\begin{array}{l}\text { Drag change } \\
\text { rate (\%) }\end{array}$ & $\begin{array}{l}\text { Calculation time } \\
\text { per case(s) }\end{array}$ \\
\hline 1 & $1.17 \mathrm{e} 6$ & 145.99 & - & 19.42 & - & 1592 \\
2 & $1.57 \mathrm{e} 6$ & 146.20 & 0.14 & 19.36 & 0.31 & 2019 \\
3 & $2.44 \mathrm{e} 6$ & 146.21 & 0.01 & 19.32 & 0.21 & 3624 \\
\hline
\end{tabular}

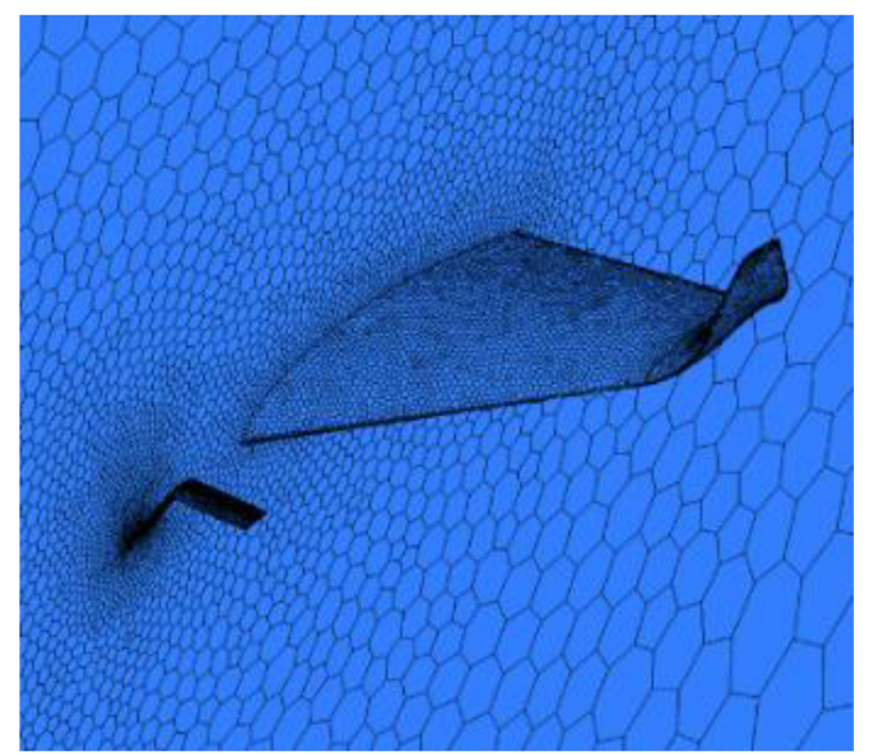

Fig. 3. Mesh strategy adopting in CFD calculation with grids of $1.57 \mathrm{e} 6$.

while $s_{p}$ and $L_{c}$ mean the span width and the chord length of delta wing.

With the aid of Ansys Fluent 2019, all the CFD tests could be applied and executed in the Workbench platform where all the simulations based on selected parametrial variables would be carried out automatically. Except for the similar boundary conditions in previous research, it should be noted that SST-kw is proposed as the turbulence model to have more accurate and robust simulation results in terms of steady flow in this article.

With the initiative geometrical parameters, the grid independent verification by means of CFD calculation is carried out at first to decide the right mesh strategy to adopt in the following optimization [12]. With the similar boundary conditions and algorithms settings in previous research [6], three cases varied with the mesh quantities of $1.17 \mathrm{e}^{6}, 1.57 \mathrm{e}^{6}$ and $2.44 \mathrm{e}^{6}$ at the speed of $V=60 \mathrm{~km} / \mathrm{h}$ are calculated and their results are listed and compared (see Tab. 1). Referring to lift and drag values, that of $1.57 \mathrm{e}^{6}$ is considered as the optimal mesh which has assured the simulation precision with relatively less mesh to reduce process time, that saves as much as $44.3 \%$ of total time cost (see Fig. 3), which would also provide virtual results with enough details to describe the flow around the wings [13].

\section{Multi-level optimization strategy}

\subsection{Strategy of multi-level optimization}

According to previous researches and test experience, this article has choses 5 parameters and 4 parameters respectively to realize the geometrical models of the delta wing and canard wing as followings.

In the part of delta wing, the aerofoil shape is selected as FX63-137 as its lift advantage and the thickness to install the fans, thus the value between $4^{\circ}$ and $6^{\circ}$ are set for the incident angle $\alpha_{i n 1}$. On one hand, the chord length $L_{c 1}$ is varied from 1.3 to $1.5 \mathrm{~m}$ to have the maximum lift; on the other hand, the ratio of plain wing tip $\lambda_{1} \in[0.4 \sim 0.6]$, ratio of winglet tip $\lambda_{s w} \in[0.2 \sim 0.4]$, span of plain wing $s_{p 1} \in[0.8 \sim 0.9] \mathrm{m}$, span of winglet $s_{p w 1} \in[0.1 \sim 0.2] m$ are draw to reach the optimal conception.

In the part of canard wing, the aerofoil shape is selected as NACA6412 as the value between $\alpha_{i n 1}+0^{\circ}$ and $2^{\circ}$ are set for the incident angle $\alpha_{i n 2}$. Besides, other parameters concerned are set as following: chord length $L_{c 2} \in[0.1 \sim 0.2] \mathrm{m}$, span of the wing $s_{p 2} \in[0.5 \sim 0.7] \mathrm{m}$, height of upper part $h_{u p} \in[0.4 \sim 0.6] \mathrm{m}$.

To simplify the optimization work and reduce the calculating cases in CFD simulation, a quick and effective multilevel method is presented and adopted in the design and optimization of the Tube-Fan hybrid UAV featuring with canard configuration (see Fig. 4) [14]:

Above all, the suitable strategy is discussed to distribute the lift providing by delta wing and canard wing [15]: First step of optimization, the optimization based on 5 parameters is carried on to determine the shape of the delta wing with satisfying the lift goal of delta wing; Second step of optimization, based on the optimized shape obtained in First step, the optimization based on 4 parameters in canard modelling is continued to reach the final optimized objects of the Tube-Fan hybrid UAV.

In order to simplify the optimization calculations, the equation (1) would be converted into two sequential but individual single-object optimization questions, which means that each one consists of only one optimization function equipped with fewer parameters. Besides, two new terms of $G_{1}$ and $G_{2}$ are defined as the goal functions respectively in delta wing and canard wing:

$$
\left\{\begin{array}{l}
G_{1}=F_{x 1} \cdot s_{w 1} \cdot L_{c 1} \\
G_{2}=F_{x} \cdot s_{w 2} \cdot L_{c 2}
\end{array}\right.
$$




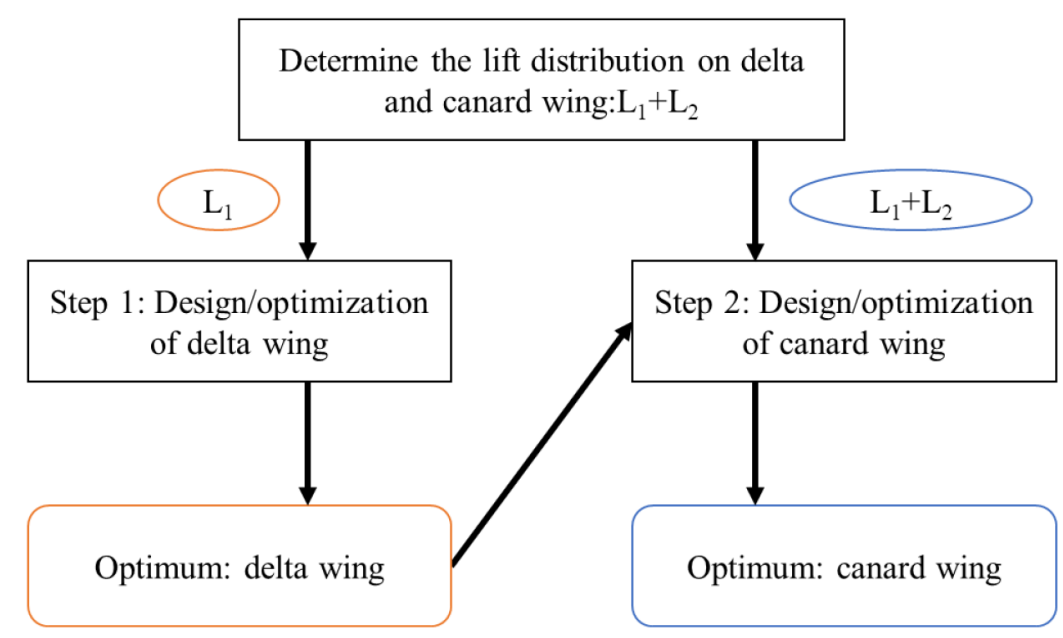

Fig. 4. The diagram of design and optimization method.

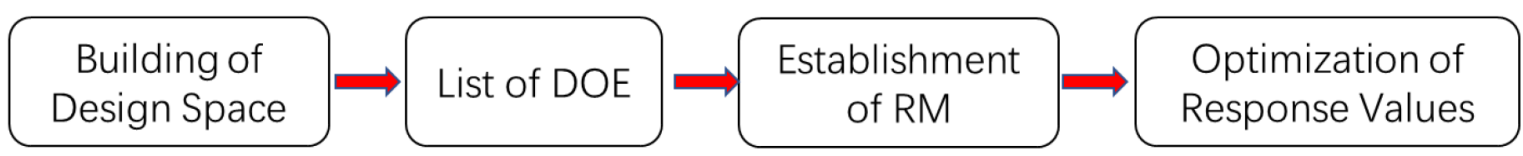

Fig. 5. Practical procedure of response surface methodology.

where $F_{x 1}$ represents the drag of the individual canard wing, without the influence of canard structure, while $s_{w 1}$ and $s_{w 2}$ are respectively the upper surface area of the delta and canard wing.

The first single-object optimization problem to solve for the delta wing

$$
\left\{\begin{array}{l}
\operatorname{Min} G_{1}\left(\alpha_{i n 1}, L_{c 1}, S_{p 1}, \lambda_{1}, \lambda_{s w}\right) \\
\text { s.t. } F_{y 1}\left(\alpha_{i n 1}, L_{c 1}, S_{p 1}, \lambda_{1}, \lambda_{s w}\right) \geq F_{y 1}^{\prime}
\end{array}\right.
$$

The second single-object optimization to solve for the canard wing

$$
\left\{\begin{array}{l}
\operatorname{Min} G_{2}\left(\alpha_{i n 2}, L_{c 2}, S_{p 2}, h_{u p 2}\right) \\
\text { s.t. } F_{y}\left(\alpha_{i n 2}, L_{c 2}, S_{p 2}, h_{u p 2}\right) \geq F_{y}^{\prime}
\end{array}\right.
$$

where $F_{y 1}^{\prime}$ and $F_{y}^{\prime}$ are respectively the minimum lifts of the delta wing and total lift, which should respect the relations as followings (see Eq. (5)), where their values are determined respectively as $F_{y 1}^{\prime}=145 N$ and $F_{y 1}^{\prime}=10 N$ in this application.

$$
F_{y 1}^{\prime}+F_{y 2}^{\prime}-50 \% F_{y 2}^{\prime} \geq 150 N
$$

\subsection{Response surface methodology}

To achieve the optimized conceptual design specialized with some response variables based on the given parameters as independent input variables, the Response Surface Methodology [16], which combines the advanced Design Of Experiment (DOE), modern statistical and mathematical techniques, is adopted in this article. In consequence, the RSM of this article defines a second-order functional as the response surface to fit the relationship between the single response $y$ and design matrix with input variables $\left(x_{1}, x_{2}, \ldots, x_{k}\right)$ with unknown parameters $\beta_{i j}$ of the RSM [17]:

$$
y=\beta_{0}+\sum_{i=1}^{k} \beta_{i} x_{i}+\sum_{i=1}^{k} \beta_{i i} x_{i}^{2}+\sum_{i<} \sum_{j=2}^{k} \beta_{i j} x_{i} x_{j}+\varepsilon
$$

By defining the vectors of $\boldsymbol{x}$ and $\boldsymbol{\beta}$, where $\boldsymbol{x}$ represents a function of location that is considered as the DOE design space while $\boldsymbol{\beta}$ would be decided by ordinary least squares (OLS) the equation (6) could be written in matrix notation as below, in which $\varepsilon$ is the term of random error (equal to zero at simulated points):

$$
y=\boldsymbol{x} \boldsymbol{\beta}+\varepsilon
$$

Above all, in this article the optimization of RSM is practically carried out in four successive steps as followings (see Fig. 5) [18]: First of, the design space is built with all of the ranges of input variables; secondly, limited cases are generated to form the design of experiments whose results would be obtained by means of CFD method; thirdly, response surfaces are established with suitable algorithms based on DOE results; lastly, verified and modified by a few new experiment points, the optimal value is proposed.

It's noted that the genetic algorithm is chosen in RSM to profit from the genetic population technology that would be solved parallelly. On one hand, by adapting the own fitness function for the best approaching, the accuracy is achieved as well as the robust [19]; on other hand, benefiting from the capacity of expressing of weighted 


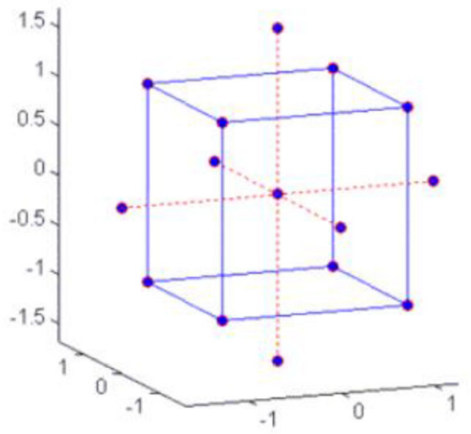

(a)

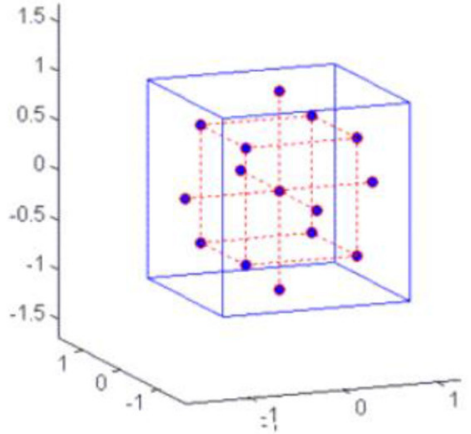

(b)

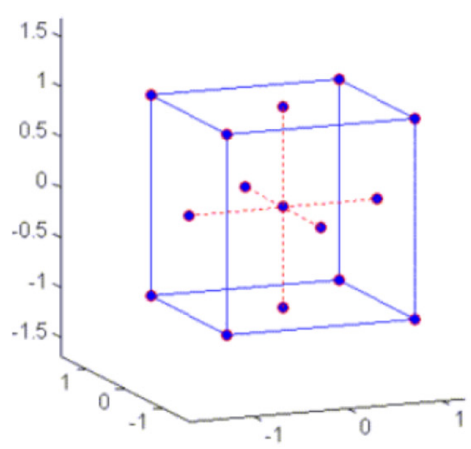

(c)

Fig. 6. Three types of CCDs. (a) Circumscribed. (b) Inscribed. (c) Face-centered.

average in the response surface [20], the genetic aggregation makes it possible to iterate the most appropriate response surface [21].

\subsection{Central composited design}

To minimize the number of experiments and accelerate the progress of optimizing searching, it's important and worthy to select a propriate method for the design of experiments. Central Composite Design (CCD) is considered as one of the most accepted means which could provide a screening set with the overall trends for a better guide the choice of options in parametrial optimization. Central Composite Design, that is also named as Box-Wilson Central Composite Design, has three main advantages which are preferred in this research: (1) Good sequence which could help us understand the relationships of the selected parameters in the future research; (2) Excellent efficiency which would help us save much time with numbers of input values; (3) Flexible application which would meet the variable need in this article.

CCD features with an imbedded five-level fractional factorial design with centre points of zero defined by the input parameters, hence around which the five-level codes are represented by $[-1,-\alpha, 0,+\alpha, 1]$, where $[-1,1]$ are recorded according to the lower and upper limit of the input range as well as the star point $\alpha$ depends on different types of CCDs [22]. In terms of the location of star points with the value of $|\alpha|$, there are three types of CCDs commonly used in experimental designs: circumscribed, inscribed and facecentred CCDs (see Fig. 6).

In our article, the circumscribed CCD is firstly abandoned as some bounds of our input parameters have already reached their limitations in the geometrical design. Although without rotatability, the face-cantered CCD has been proved to have less complexity and better accuracy compared with inscribed CCD. Therefore the Inscribed CCD is applied in the DOE of the RSM optimization in this article, as well as the G-optimality is adopted to minimise the maximum leverage value of sample points to increase [23].

\section{Results}

\subsection{Optimal conception}

After two steps of RSM procedure, the multi-level optimization come out to realize the optimal conceptual design of the delta and canard wing modelled by the 9 parameters (see Tab. 2 and Fig. 7). Besides, benefiting from CFD results [24], some principal aerodynamical performance are gained and listed for further research (see Tab. 3). Otherwise, the original conception with initial values of these 9 parameters are listed to compare with, which turns out that the lift produced by the wing parts are effectively improved $(+5.37 \%)$ by the multilevel optimization, which would satisfy the expected requirement of the MTOW.

Referring to Table 2, the max error between the RSM values and CFD predictions is less than $0.05 \%$ thus it turns out that the response surfaces calculated in the delta wing optimization have an exceptional accuracy in various range. However, besides of the performances with mention as above, in the future it would necessary to take some other performances into account, such as the structural strength, the fabrication cost and so on.

Furthermore, some important results of aerodynamic performances which are calculated in CFD method are concluded as following (see Tab. 3). Compared with the assumption in Section "Distribution of lift", the delta and canard wing in the CFD simulation, where $F_{y 1}^{0}=145.13 \mathrm{~N}$ and $F_{y 2}=10.05 \mathrm{~N}$, is proved to respect the relationship of the distribution in equation (5) as following.

$$
F_{y 1}^{0}+F_{y 2}-50 \% F_{y 2}=150.17>150 N
$$

As mentioned before, the downwash passed from canard wing could probably disturb the upper flow of the delta wing. On the cruise mode for the hybrid UAV, one the most important goal of the optimization in this article is to maximum the lift, thus the interference of the canard wing on the delta wing should be as little as possible. It has been well known that the CFD method could provide 
Table 2. The optimized parameters of the wing.

\begin{tabular}{|c|c|c|c|c|}
\hline & \multicolumn{2}{|c|}{ Parameters } & Original Values & Candidate Values \\
\hline Delta wing & $\begin{array}{l}\text { Chord } \\
\text { Sweep } \\
\text { Span o } \\
\text { Ratio o } \\
\text { Ratio o }\end{array}$ & & $\begin{array}{l}5^{\circ} \\
1.4 \mathrm{~m} \\
0.85 \mathrm{~m} \\
0.4 \\
0.3\end{array}$ & $\begin{array}{l}6.9969^{\circ} \\
1.3036 \mathrm{~m} \\
0.8520 \mathrm{~m} \\
0.4251 \\
0.3819\end{array}$ \\
\hline \multirow[t]{2}{*}{ Canard wing } & $\begin{array}{l}\text { Inciden } \\
\text { Chord } \\
\text { Span o } \\
\text { Height }\end{array}$ & & $\begin{array}{l}6^{\circ} \\
0.15 \mathrm{~m} \\
0.6 \mathrm{~m} \\
0.5 \mathrm{~m}\end{array}$ & $\begin{array}{l}7.5149^{\circ} \\
0.1000 \mathrm{~m} \\
0.6450 \mathrm{~m} \\
0.5519 \mathrm{~m}\end{array}$ \\
\hline & $F_{y}(\mathbf{N})$ & $\begin{array}{l}\text { RSM } \\
\text { CFD } \\
\text { Error } \\
\text { RSM }\end{array}$ & $\begin{array}{l}- \\
142.4002 \mathrm{~N} \\
- \\
-\end{array}$ & $\begin{array}{l}150.1228 \mathrm{~N} \\
150.0432 \mathrm{~N} \\
0.05 \% \\
20.1402 \mathrm{~N}\end{array}$ \\
\hline Aerodynamics & $F_{x}(\mathbf{N})$ & $\begin{array}{l}\text { CFD } \\
\text { Error }\end{array}$ & $\begin{array}{l}18.4685 \mathrm{~N} \\
-\end{array}$ & $\begin{array}{l}20.1486 \mathrm{~N} \\
0.04 \%\end{array}$ \\
\hline
\end{tabular}
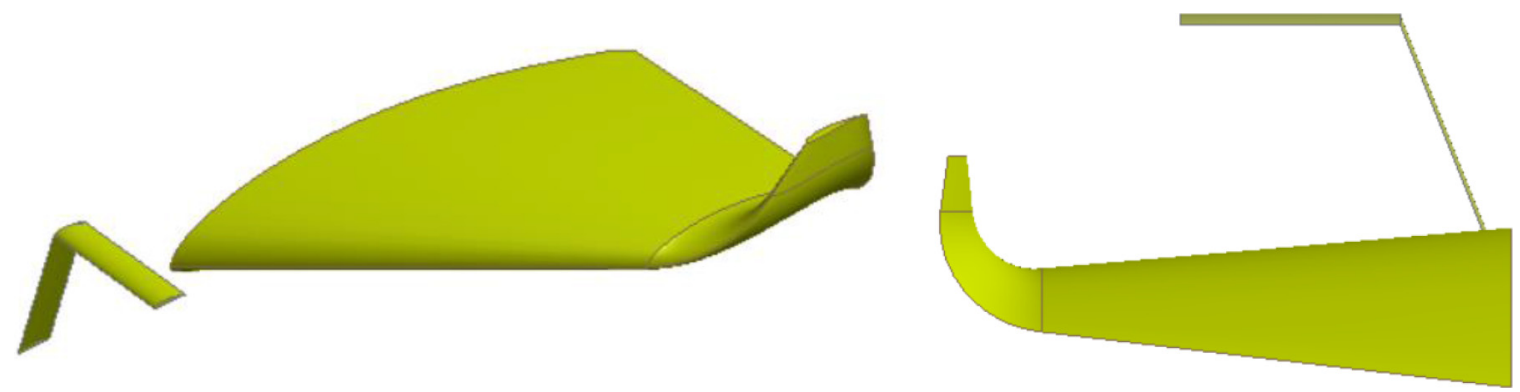

Fig. 7. Optimal design of the wings of Tube-Fan hybrid UAV.

Table 3. Aerodynamic performances of the optimized design.

\begin{tabular}{|c|c|c|c|c|c|}
\hline \multicolumn{6}{|c|}{$\mathrm{V}=60 \mathrm{~km} / \mathrm{h}$} \\
\hline \multirow{4}{*}{ First Optimization } & \multirow{3}{*}{ Delta part } & $F_{y 1}^{0}(\mathrm{~N})$ & 150.0432 & $F_{x 1}^{0}(\mathrm{~N})$ & 20.1486 \\
\hline & & $C_{L 1}^{0}$ & 0.9887 & $C_{D 1}^{0}$ & 0.1328 \\
\hline & & $C_{L 1}^{0} / C_{D 1}^{0}$ & 7.4468 & $S_{w 1}\left(\mathrm{~m}^{2}\right)$ & 1.0656 \\
\hline & \multirow{3}{*}{ Total part } & $F_{y}(\mathrm{~N})$ & 139.9949 & $F_{x}(\mathrm{~N})$ & 19.3967 \\
\hline \multirow{8}{*}{ Second Optimization } & & $C_{L}$ & 1.0124 & $C_{D}$ & 0.1403 \\
\hline & & $C_{L} / C_{D}$ & 7.2174 & $S_{w t}\left(\mathrm{~m}^{2}\right)$ & 0.9709 \\
\hline & \multirow{3}{*}{ Delta part } & $F_{y 1}(\mathrm{~N})$ & 10.0484 & $F_{x 1}(\mathrm{~N})$ & 0.7518 \\
\hline & & $C_{L 1}$ & 0.7448 & $C_{D 1}$ & 0.0557 \\
\hline & & $C_{L 1} / C_{D 1}$ & 13.3652 & $S_{w 1}\left(\mathrm{~m}^{2}\right)$ & 0.0947 \\
\hline & \multirow{3}{*}{ Canard part } & $F_{y 2}(\mathrm{~N})$ & 150.0432 & $F_{x 2}(\mathrm{~N})$ & 20.1486 \\
\hline & & $C_{L 2}$ & 0.9887 & $C_{D 2}$ & 0.1328 \\
\hline & & $C_{L 2} / C_{D 2}$ & 7.4468 & $S_{w 2}\left(\mathrm{~m}^{2}\right)$ & 1.0656 \\
\hline
\end{tabular}




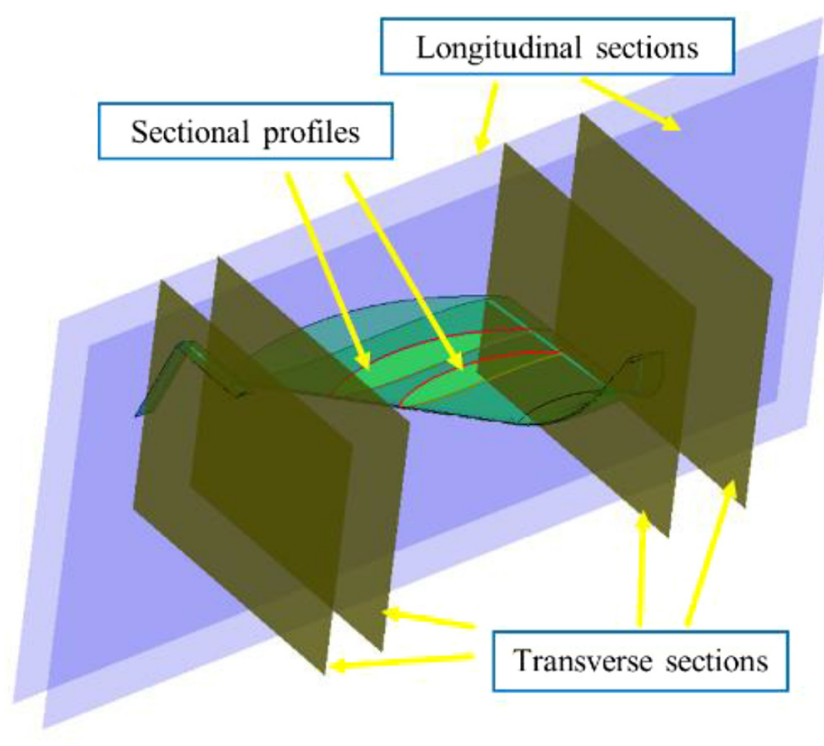

Fig. 8. Sectional plans and profiles around the wing.
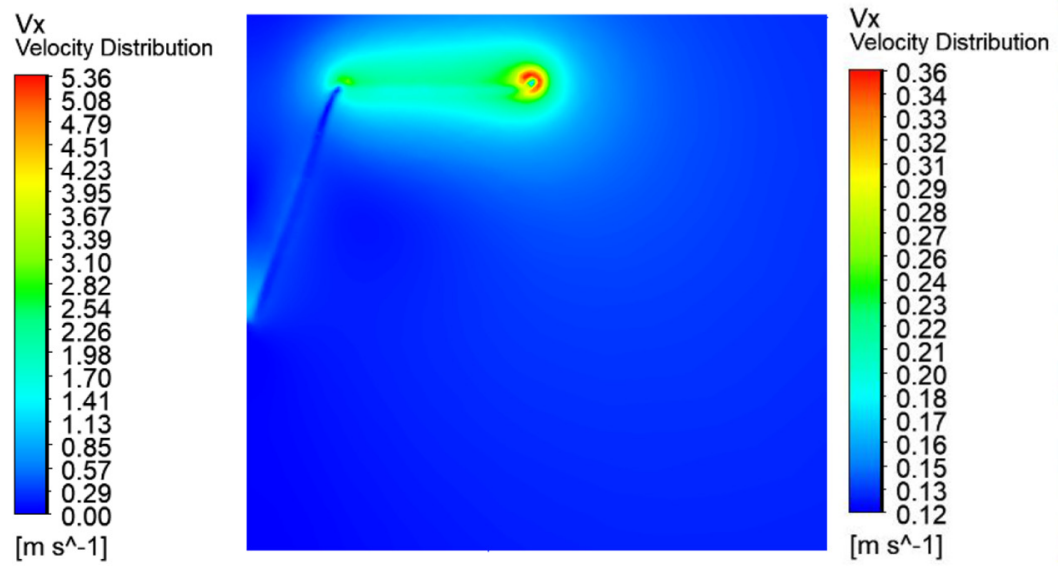

(a) virtual results to study the mechanics in the fluid dynamics, thus several sectional plans and profiles are created around the wings in the CFD post results as below (see Fig. 8), to help illustrate the interference of the canard wing. The longitudinal sections are numbered as X1, X2, $\mathrm{X} 3$, and $\mathrm{X} 4$ from the front to the back, while the transverse sections at Z1 and Z2 from middle to the wing, by which two sectional profiles on the delta wing are created.

Based on the CFD-post module of the Ansys Workbench, the virtual details of the flow field simulation obtained by Fluent are illustrated and digitized to study the flow mechanism which helps the researchers to develop the conception. Thus, the velocity contours of auxiliary planes $\mathrm{X} 1, \mathrm{X} 2, \mathrm{X} 3$ and $\mathrm{X} 4$ are presented as following to investigate the flow tendency influenced by the canard wing as well as the velocity distribution in vertical sections (see Fig 9-Fig 12), to figure out the influence by the canard configuration. By comparison of the distribution of velocity at X1, X2, X3 and X4, the flow before the delta wing is quite disturbed by the canard wing (see Fig. 9), in which two additional zones of vortices generate in X2 plan just along the transition and end parts of the canard (see Fig. 10).

Fig. 9. Distribution of tangential velocity at X1. (a) Contour with canard. (b) Contour without canard.

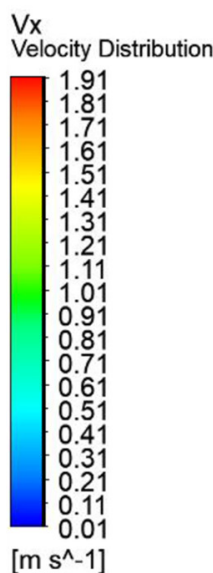

$\left[\mathrm{m} \mathrm{s}^{\wedge}-1\right]$

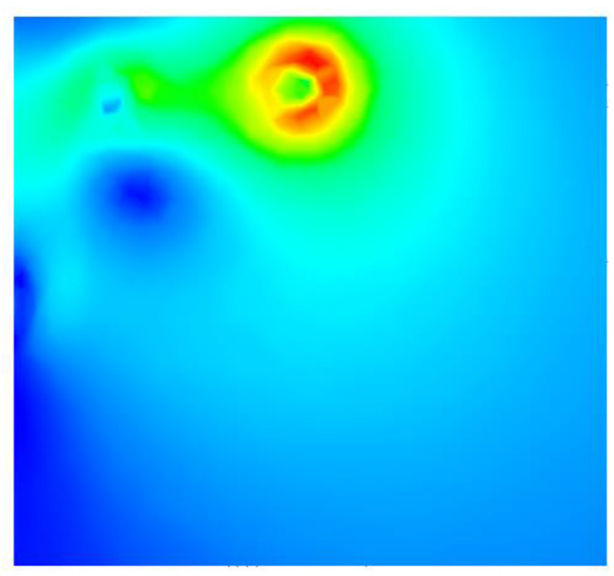

(a)
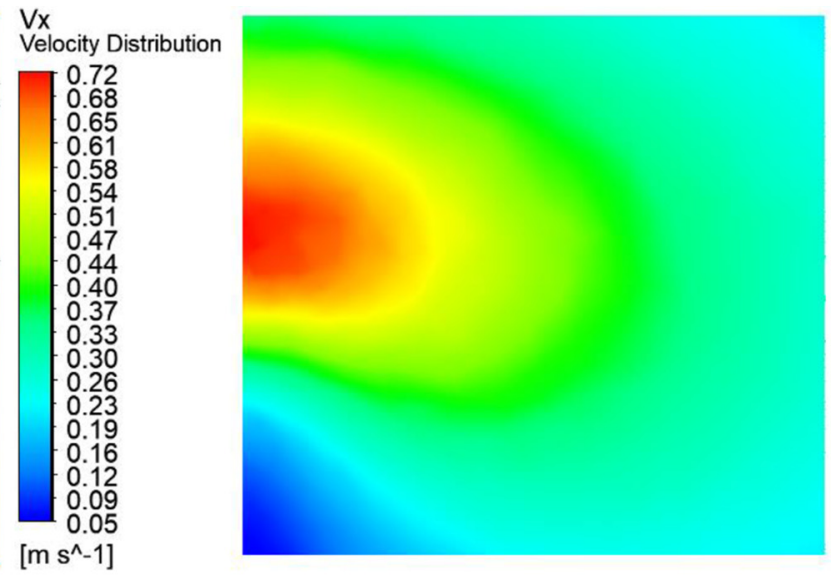

(b)

Fig. 10. Distribution of tangential velocity at X2. (a) Contour with canard (b) Contour without canard. 


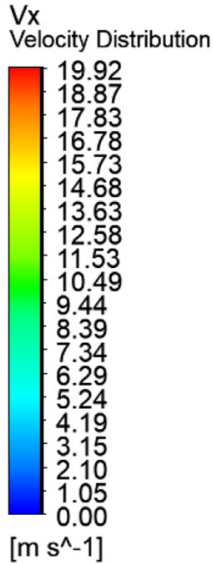

$\left[\mathrm{m} \mathrm{s}^{\wedge}-1\right]$

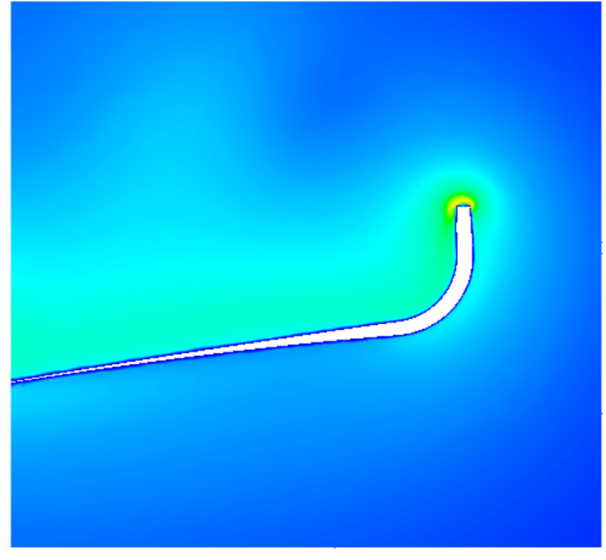

(a)

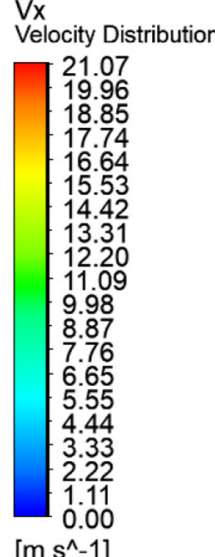

$\left[\mathrm{m} \mathrm{s}^{\wedge}-1\right]$

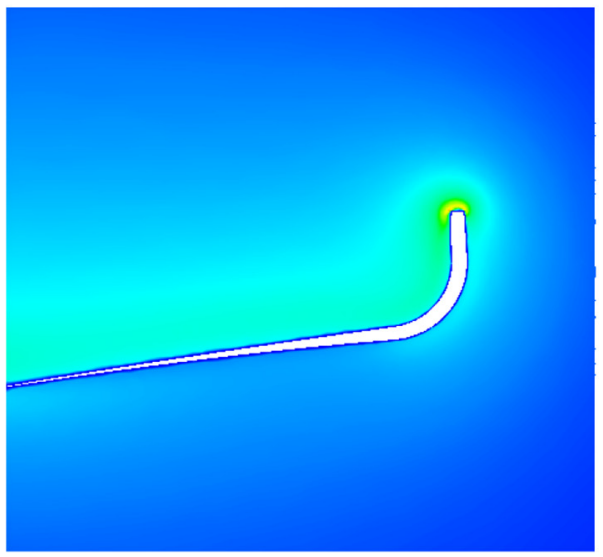

(b)

Fig. 11. Distribution of tangential velocity at X3. (a) Contour velocity with canard. (b) Contour without canard.

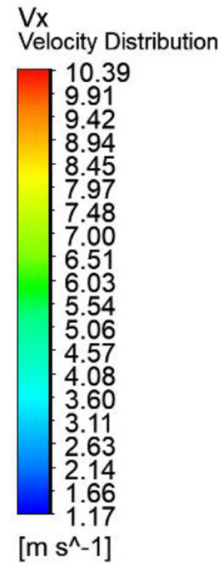

$\left[\mathrm{m} \mathrm{s}^{\wedge}-1\right]$

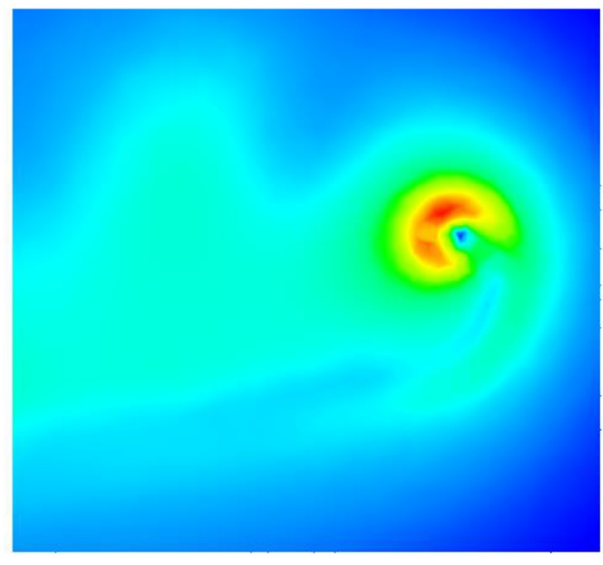

(a)

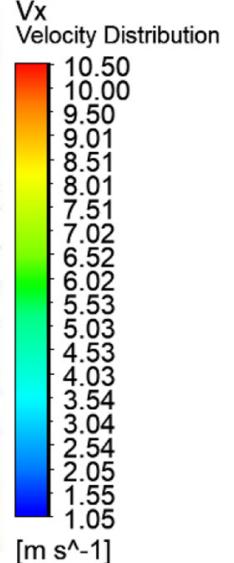

$\left[\mathrm{m} \mathrm{s}^{\wedge}-1\right]$

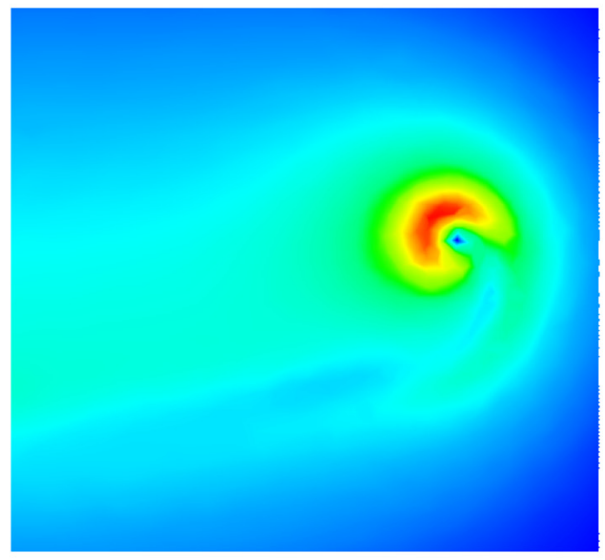

(b)

Fig. 12. Distribution of tangential velocity at X4. (a) Contour with canard. (b) Contour without canard.

Afterward, when the flow from the canard wing are crossing the delta wing (see Fig. 11), the velocity distribution keeps the almost same as that without canard (see Fig. 12), in which the flow will escape from the down surface to the up surface by winglet. After observation the velocity distribution, two reasons are concluded: (1) the new vortices zones are quite far from the winglet in the optimized conceptual design; (2) the strength of the vortices (maximum tangential velocity is $1.91 \mathrm{~m} / \mathrm{s}$ in Fig. 10) by the canard are much less than that by the delta wing (maximum tangential velocity is $21.07 \mathrm{~m} / \mathrm{s}$ in Fig. 14).

Besides, the expected slight interference of the canard wing is testified by the distribution of pressure coefficient (see Eq. (9)) on different sections, Z1 and Z2, of aerofoils on the delta wing, where their locations are still at the horizontal range of the canard wing(see Fig. 13). Even observing the little descent of $C_{p}$, it could be concluded that, on the delta wing behind the canard configuration in the optimal design, the curves $C_{p}-x / c$ on two aerofoil sections maintain almost still as that without canard wing.

$$
C_{p}=\frac{p}{\frac{1}{2} \rho v^{2}}
$$

\subsection{Improvement of lift performance}

In low speed aircraft at $M a<0.3$, the most evident advantage of the canard wing is on the lift performance, which will augment the vertical force to support more weight and increase the aerodynamic performance, especially at the quite high attack angle. The lift of the delta and canard wing have been predicted with different attack angles by means of CFD method to demonstrate the influence of the canard wing on the Tube-Fan hybrid UAV (see Figs. 14 and 15), in which "Delta wing(without canard)" represents the performance 


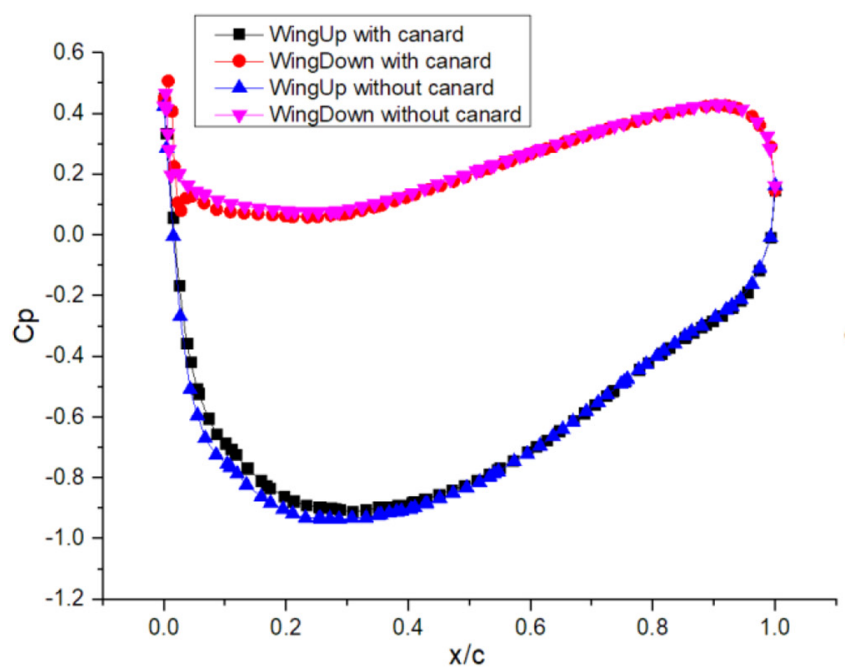

(a)

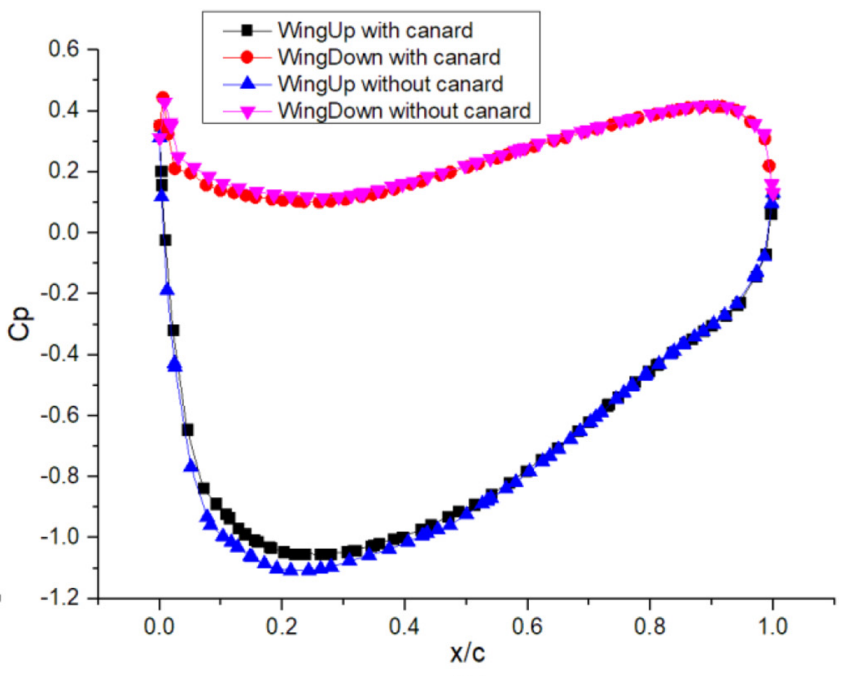

(b)

Fig. 13. $C p-x / c$ on of the delta wing at $\mathrm{Z} 1$ and $\mathrm{Z} 2$ (a) airfoil at $\mathrm{Z} 1$, (b) airfoil at $\mathrm{Z} 2$.

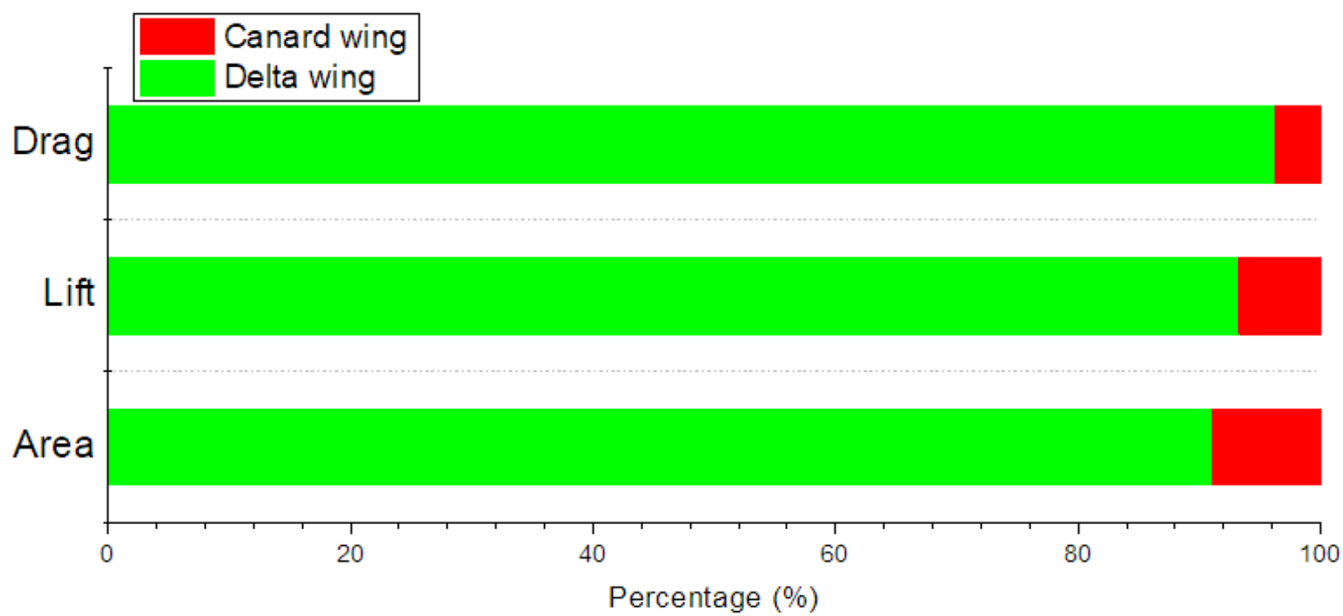

Fig. 14. Comparison of the canard and delta wing at $\mathrm{AOA}=0^{\circ}$.

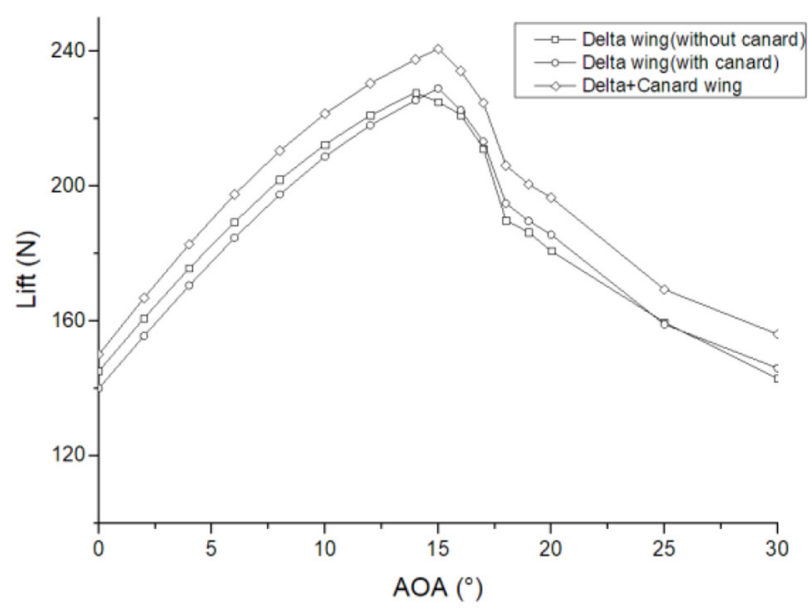

(a)

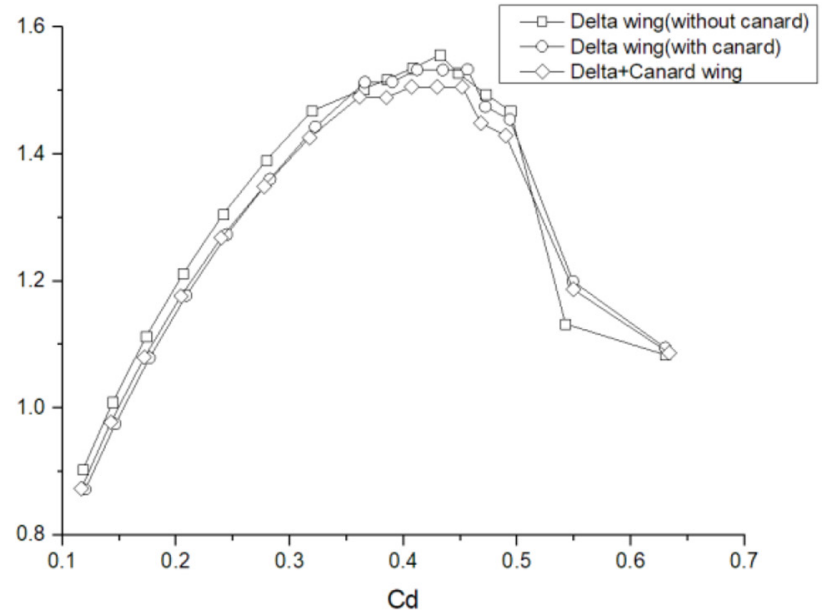

(b)

Fig. 15. Lift and $C_{L} / C_{D}$ of the delta \& canard wing at different AOA. (a) Lift-AOA. (b) $C_{L}-\mathrm{AOA}$. 


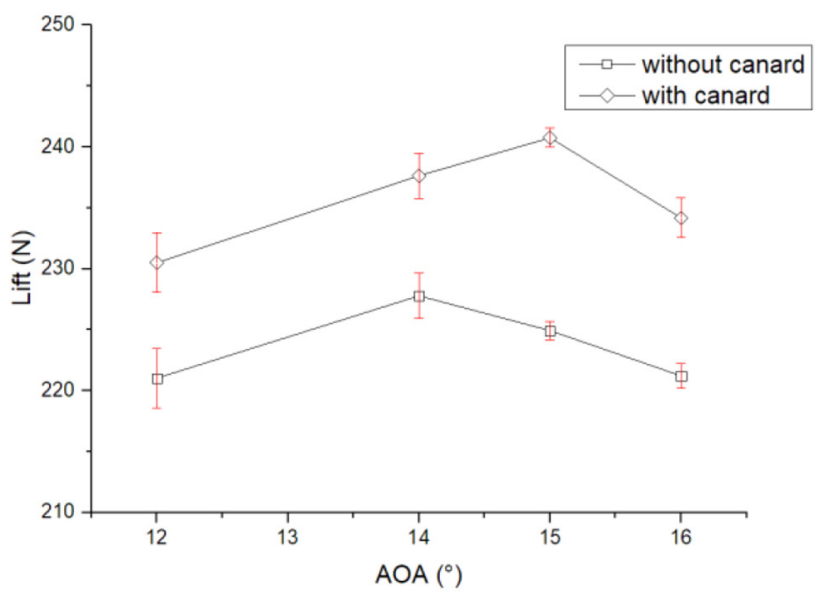

(a)

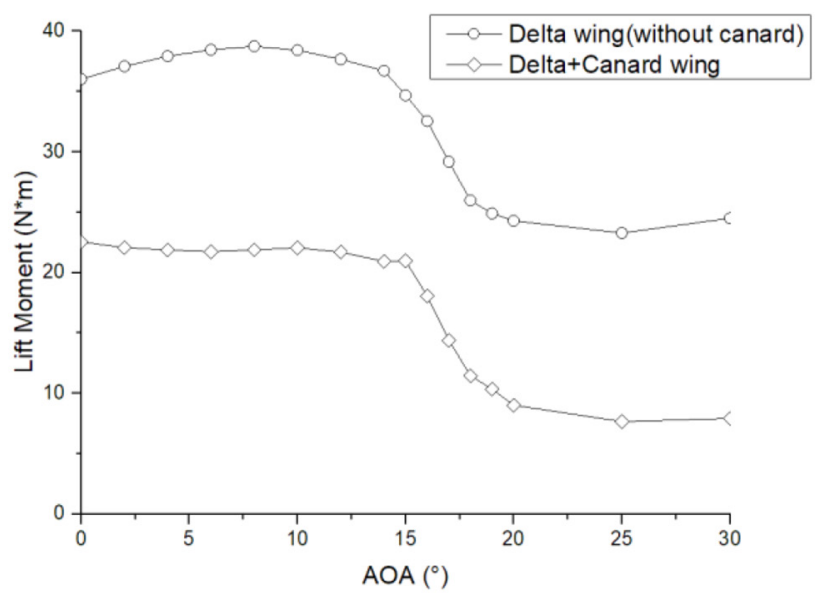

(b)

Fig. 16. Lift and lift moment of the wing with/without canard at different AOA. (a) Lift-AOA. (b) Lift Moment - AOA.

with the solo optimized delta wing while "Delta wing(with canard)" and "Delta + Canard wing" represents that with optimized delta and canard wing.

In order to keep the most part still of last conceptual design, the canard wing adopted in the hybrid UAV is quite small compared with the delta wing, whose upper surface area is $9.76 \%$ of the delta wing (see Fig. 14.) Simulation results by CFD method show that the canard wing provides $6.70 \%$ lift and only $3.73 \%$ drag of the total system, which signifies that it could both increase the lift the $C_{l} / C_{d}$. For the reason why the coefficient of lift of the canard is less than that of the delta wing, it can be explained easily that as the aerofoil type adopted for the canard wing, naca6412, is specialized with low drag performance and slight disturbance for the outflow, but its lift performance isn't as excellent as that of fx63-137 for the delta wing.

In previous researches, it's widely known that the delta wing could be quite interfered by the downwash of the canard wing which would inevitably cause lift reduce, but the total lift will be improved from $3.34 \%\left(\mathrm{AOA}=0^{\circ}\right)$ to $7.03 \%\left(\mathrm{AOA}=15^{\circ}\right)$ compared with that of solo delta wing (see Fig. 15). By comparing the change ratio of the lift with and without canard (see the error bar in Fig. 16), it's observed that not only the angle of stall with canard wing is estimated as $15^{\circ}$ which is larger than that without canard wing $\left(14^{\circ}\right)$, but also the lift curve with the canard wing would possess the gentler trend at the curve peak with a smaller change ratio. Moreover, given a gravity centre as the middle point of the chord aerofoil of the delta wing, the lift moment calculated by CFD simulation showed that the canard could dramatically descend the moment that raises the head of the UAV when the AOA changes. Therefore, it can be proved and demonstrated that the canard wing would help prevent the wing into stall station with a gentle change.

Furthermore, the interference of canard on the delta wing could be slightly at high attack angle as well. The distribution of vector around the delta wing behind the canard wing at Z1 and Z2 plans are compared as following (see Figs. 17 and 18), which turns out to be nearly identical with that without canard. Hence, it's testified again that the canard configuration in the optimal conception has least interference on the main delta wing while the increment of lift and lift moment at high attack angle is almost contributed only by the canard wing with no additional and negative influence on the delta wing.

\section{Conclusion}

In the innovative Tube-Fan hybrid UAV, the multilevel optimization approach is successfully adapted to introduce the canard configuration into the conceptual design. Indeed, coupled with RSM and DOE, a two-step optimization is therefore proposed to discuss in this article, then it's adopted into the design and RSM optimization to greatly simplify the design points based on CFD method with appropriate mesh strategy and algorithm.

With an optimal strategy of lift distribution by iterated decision, the parametrial design and optimization of delta wing and canard wing are carried out in sequence. Several coefficients are defined to simplify the multi-objective goals into a one-goal optimization with respecting design conditions. Thus, the final model of the Tube-Fan hybrid UAV is optimized with the cooperation of RSM optimization and CFD simulation, which is detailed and demonstrated with its aerodynamic performances listed in the article.

Furthermore, virtual results predicted by CFD simulation help us research on the influence of the canard wing, which proves that the optimal conception has profited the positive effect of canard configuration thus only the slight coupled influence is imposed on the delta wing.

On the other hand, we should admit that only several important aerodynamic performances are considered in this article while more studies and tests on the Tube-Fan hybrid UAV will be carried on based on the results 


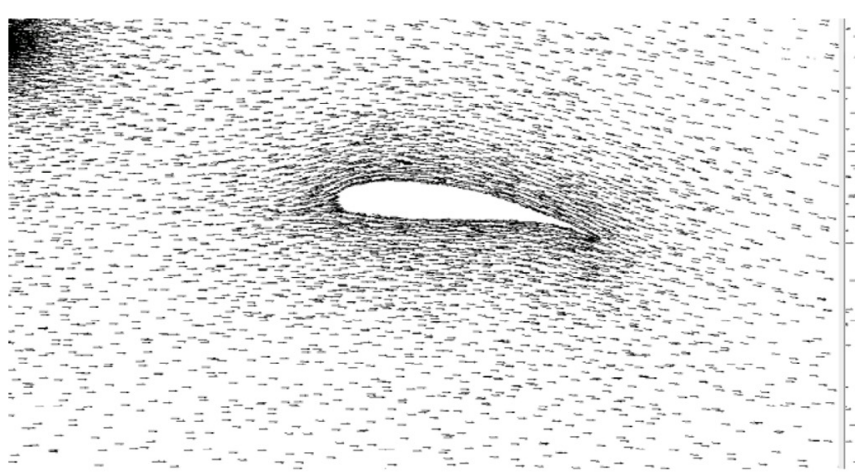

(a)

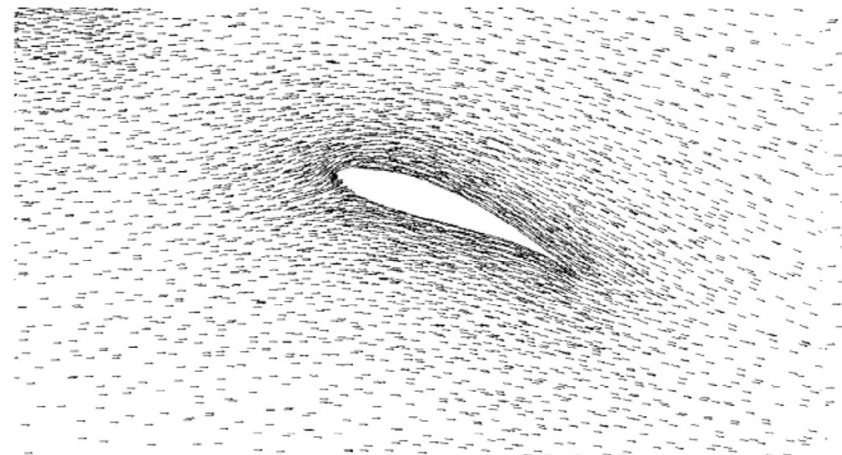

(c)

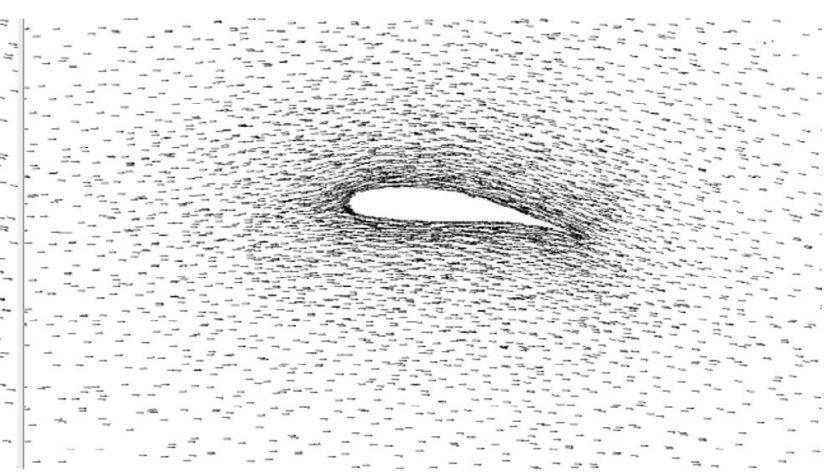

(b)

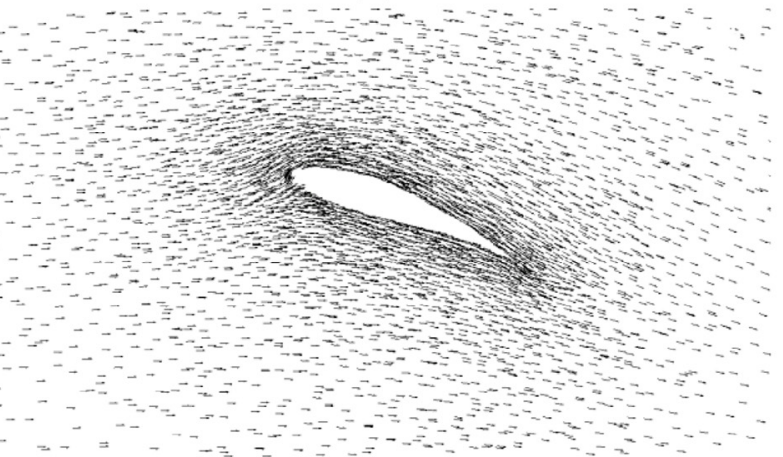

(d)

Fig. 17. Vector distribution of velocity on the $\mathrm{Z} 1$ plan of the delta wing with/without canard (a) with canard at $\mathrm{AOA}=0^{\circ},(\mathrm{b})$ without canard at $\mathrm{AOA}=0^{\circ}$, (c) with canard at $\mathrm{AOA}=14^{\circ}$, (d) without canard at $\mathrm{AOA}=14^{\circ}$.

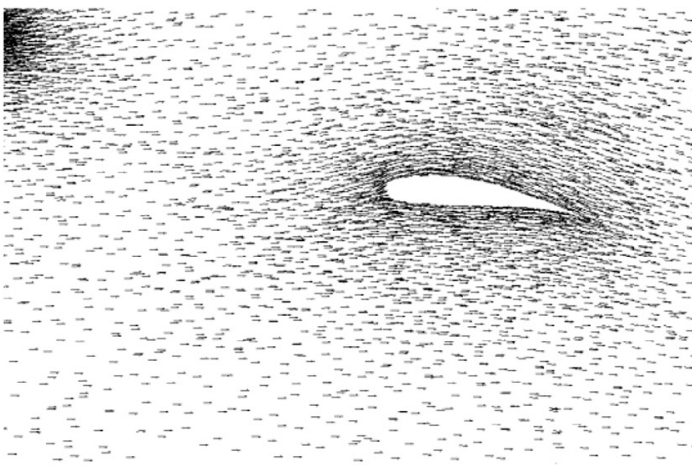

(a)

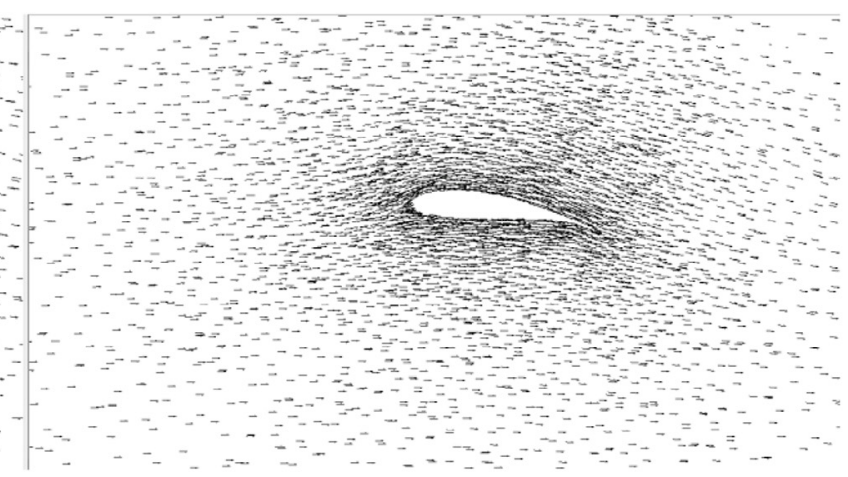

(b)

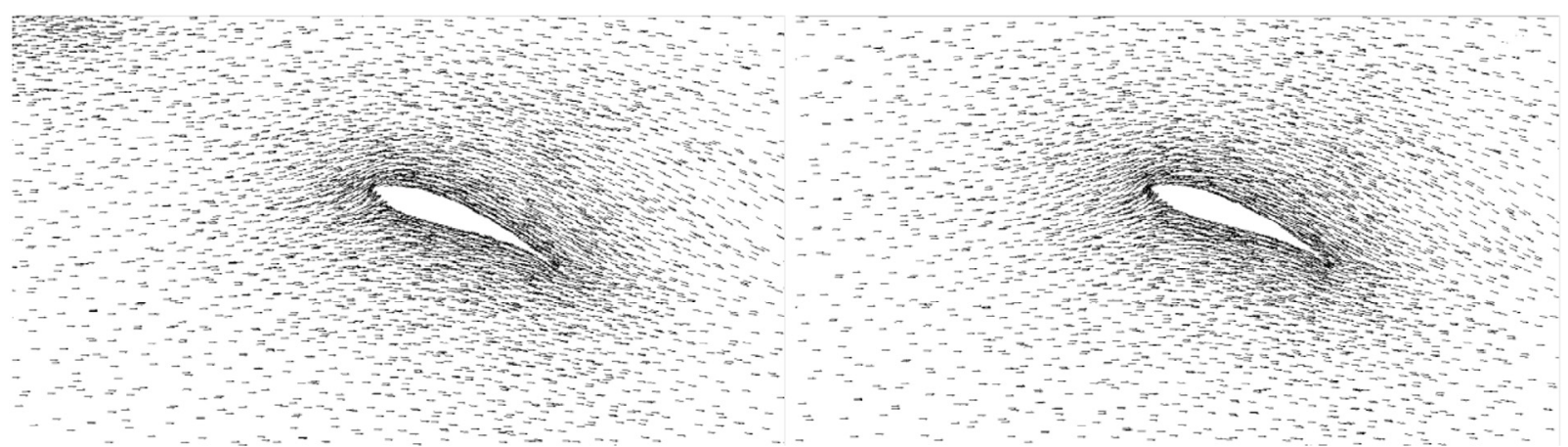

(c)

(d)

Fig. 18. Vector distribution of velocity on the Z2 plan of the delta wing with/without canard (a)with canard at $\mathrm{AOA}=0^{\circ},(\mathrm{b})$ without canard at $\mathrm{AOA}=0^{\circ},(\mathrm{c})$ with canard at $\mathrm{AOA}=14^{\circ},(\mathrm{d})$ without canard at $\mathrm{AOA}=14^{\circ}$. 
obtained in this article, such as the design of VTOL and propulsion system, the structural conception, optimization and additive manufacture of the wing and fuselage, the model and simulation of the dynamical control system, and so on. Therefore, more objects will be taken into account and the design of the wing parts could be optimized iteratively in the subsequent research in this project for the Hybrid Tube-Fan UAV.

\section{References}

1. R. Czyba, M. Lemanowicz, Z. Gorol, T. Kudala, Construction Prototyping, Flight Dynamics Modeling, and Aerodynamic Analysis of Hybrid VTOL Unmanned Aircraft, J. Adv. Transp. 2018, 1-15 (2018)

2. C. De Wagter et al., Design, control, and visual navigation of the DelftaCopter VTOL tail-sitter UAV, Journal of Field Robotics 35, 937-960 (2018)

3. P. Panagiotou, P. Kaparos, C. Salpingidou, K. Yakinthos, Aerodynamic design of a MALE UAV, Aerosp. Sci. Technol. 50, 127-138 (2016)

4. M. Hassanalian, A. Abdelkefi, Classifications, applications, and design challenges of drones: a review, Prog. Aerosp. Sci. 91, 99-131 (2017)

5. A.S. Saeed, A.B. Younes, C. Cai, G. Cai, A survey of hybrid Unmanned Aerial Vehicles, Prog. Aerosp. Sci. 98, 91-105 (2018)

6. P. Marques, A. Maligno, S. Dierks, A. Bachouche, Flight dynamics principles of canard aircraft: implications for UAV configuration decision, Int. J. Unmanned Syst. Eng. 1, 12-30 (2013)

7. X.D. Li Zhonghua, H. Tian, Flight dynamics characteristics and current situation of canard aircraft, Jiangsu Sci. Technol. Inf. 8, 60-61 (2016)

8. J. Muchowski, M. Szumski, A. Krzysiak, Aerodynamic concept of the UAV in the gyrodyne configuration, Trans. Aerosp. Res. 2018, 49-66 (2019)

9. N. Homainejad, C. Rizos, Application of multiple categories of unmanned aircraft systems (UAS) in different airspaces for bushfire monitoring and response, in International Archives of the Photogrammetry, Remote Sensing and Spatial Information Sciences - ISPRS Archives, 2015, pp. 55-60

10. S. Guessasma, D. Bassir, Optimization of the mechanical properties of virtual porous solids using a hybrid approach, Acta Mater. 58, 716-725 (2010)
11. S. Guessasma, D.H. Bassir, Identification of mechanical properties of biopolymer composites sensitive to interface effect using hybrid approach, Mech. Mater. 42, 343-353 (2010)

12. S. Kaganski, J. Majak, K. Karjust, S. Toompalu, Implementation of key performance indicators selection model as part of the enterprise analysis model, Proc. CIRP 63, 283-288 (2017)

13. T. Eiskop, A. Snatkin, K. Karjust, E. Tungel, Production monitoring system design and implementation, Proc. Estonian Acad. Sci. 67, 10-16 (2018)

14. F.X. Irisarri, D.H. Bassir, N. Carrere, J. F. Maire, Multiobjective stacking sequence optimization for laminated composite structures, Compos. Sci. Technol. 69, 983-990 (2009)

15. P. Wei, Y. Liu, Z. Li, A multi-discretization scheme for topology optimization based on the parameterized level set method, Int. J. Simul. Multidiscip. Des. Optim. 11, 1-10 (2020)

16. J. Fang, Z. He, Analysis of response surface designs to outlier, in: Proceedings of the International Conference on E-Business and E-Government, ICEE 2010, pp. 2648-2651

17. H. Hamdani, B. Radi, A. El Hami, Optimization of solder joints in embedded mechatronic systems via Kriging-assisted CMA-ES algorithm, Int. J. Simul. Multidiscip. Des. Optim. 10, 1-16 (2019)

18. R.O. Bahebshi, A.T. Almaktoom, Heuristic dynamic approach to perishable products in presence of deterioration effect, Int. J. Simul. Multidiscip. Des. Optim. 10, 1-12 (2019)

19. J. Majak, M. Pohlak, Optimal material orientation of linear and non-linear elastic 3D anisotropic materials, Meccanica 45, 671-680 (2010)

20. X. Tang, D.H. Bassir, W. Zhang, Shape, sizing optimization and material selection based on mixed variables and genetic algorithm, Optim. Eng. 12, 111-128 (2011)

21. J. Majak, S. Hannus, Orientational design of anisotropic materials using the hill and Tsai-Wu strength criteria, Mech. Compos. Mater. 39, 509-520 (2003)

22. Z. Zhang, Z. He, Z. Liu, A comparative study of three central composite designs in response surface methodology, J. Shenyang Inst. Aeronaut. Eng. 24, 87-91 (2007)

23. S.H. Munson-Mcgee, D- and G-optimal experimental designs for the partition coefficient in freeze concentration, J. Food Eng. 121, 80-86 (2014)

24. R. Prasad, S. Choi, Variable-fidelity aerodynamic analysis of lift fan type aircraft, Aerosp. Sci. Technol. 71, 636-650 (2017) 